\title{
How big a problem is heart failure with a normal ejection fraction?
}

\author{
Frans H Rutten associate professor of general practice ${ }^{1}$, Andrew L Clark professor of clinical \\ cardiology $^{2}$, Arno W Hoes professor of clinical epidemiology and general practice ${ }^{1}$
}

${ }^{1}$ Julius Centre for Health Sciences and Primary Care, University Medical Centre Utrecht, Utrecht, The Netherlands; ${ }^{2}$ Department of Cardiology, Hull York Medical School, University of Hull, Castle Hill Hospital, Cottingham, UK

Much uncertainty exists around heart failure with a normal ejection fraction, beginning with its diagnosis; there are no clinical features that distinguish it from heart failure with reduced ejection fraction. ${ }^{12}$ On echocardiography the filling capacity of the left ventricle can at best be measured only indirectly. Estimates of the prevalence of heart failure with a normal ejection fraction and its prognosis vary. Doubt exists about the clinical relevance of the diagnosis of heart failure with a normal ejection fraction because no treatment to date has substantially improved prognosis. Management is focused on symptom reduction and blood pressure control. ${ }^{12}$

Our preferred term is heart failure with normal ejection fraction. However the term is used interchangeably with "preserved ejection fraction" or diastolic heart failure. These seem less accurate because "preserved" suggests prior measurement of the patient's ejection fraction before the development of symptoms, which is not generally the case. "Diastolic" heart failure implies that systolic function is unaffected, which is incorrect.

\section{What is the evidence of the uncertainty? How is heart failure with normal ejection fraction diagnosed?}

A diagnosis of heart failure requires a combination of clinical features-such as breathlessness, fatigue, and ankle oedema-together with a structural or functional abnormality of the heart that impairs its ability to pump on echocardiography. ${ }^{1}$ Pump failure is typically caused by reduced contraction of the left ventricle, measured as a reduced ejection fraction. Reduced ejection fraction is almost always accompanied by impaired filling of the left ventricle, but in some patients reduced filling dominates whereas the ejection fraction is normal, and that is heart failure with normal ejection fraction.

Heart failure with reduced ejection fraction is better understood: it typically develops after myocardial infarction, when myocyte loss results in left ventricle dilation and diminished contraction (fig $1 \Downarrow$ ). ${ }^{3}$ Heart failure with normal ejection fraction often develops after longstanding hypertension. ${ }^{3}$ Compensatory left ventricular hypertrophy leads to myocardial stiffening, with reduced filling capacity of the normal sized or even small left ventricle. This leaves a ventricle with an ejection fraction in the normal range but a reduced stroke volume. Patients with heart failure with normal ejection fraction may have particularly bothersome symptoms during exercise.

\section{Misdiagnosis of mild disease is problematic}

In the early stages, heart failure with normal ejection fraction causing breathlessness (a key symptom of heart failure) may be confused with chronic obstructive pulmonary disease (COPD), obesity, or deconditioning. ${ }^{14}$ Fluid overload may be absent, particularly in patients receiving diuretics for hypertension. This may lead to underdiagnosis of heart failure with normal ejection fraction. On the other hand, age related breathlessness is common, which may cause overdiagnosis of heart failure with normal ejection fraction..$^{5-7}$

\section{Debate about cut-off levels for natriuretic peptides suggestive of heart failure}

UK guidelines recommend that the diagnosis of heart failure is ruled out in patients in primary care with B-type natriuretic peptide (BNP) levels below $100 \mathrm{ng} / \mathrm{L}$ or $\mathrm{N}$-terminal BNP (NTproBNP) below $400 \mathrm{ng} / \mathrm{L} .^{2}$ Although, NTproBNP below

\section{Correspondence to: F H Rutten f.h.rutten@umcutrecht.nl}

This is one of a series of occasional articles that highlight areas of practice where management lacks convincing supporting evidence. The series advisers are Sera Tort, clinical editor, and David Tovey, editor in chief, the Cochrane Library. To suggest a topic for this series, please email us at 


\section{What you need to know}

- There is variation in the thresholds for diagnosing heart failure with a normal ejection fraction

- Treatment of heart failure with normal ejection fraction does not improve survival: however, offer symptom relief with diuretics and treat hypertension and other comorbidities

- Further research is needed to characterise normal echocardiography in the ageing heart and to understand better the natural history of heart failure with a normal ejection fraction

$400 \mathrm{ng} / \mathrm{L}$ has a high negative predictive value (about 97\%), some of those with low levels will have heart failure with normal ejection fraction. ${ }^{8}$

Natriuretic peptides are produced by myocytes in response to increased wall tension, which is generally lower in heart failure with normal ejection fraction than in heart failure with reduced ejection fraction, in line with Laplace's law, because the diameter of the ventricle is smaller and wall thickness higher. Thus natriuretic peptide levels are lower in heart failure with normal ejection fraction than in heart failure with reduced ejection fraction and can even be in the normal range. ${ }^{9}$

Lowering the natriuretic peptide threshold for referral for echocardiography to avoid missing heart failure with normal ejection fraction would result in more testing with echocardiography. For example, based on a prospective cohort study, lowering cut-off points to $35 \mathrm{ng} / \mathrm{L}$ for BNP and $125 \mathrm{ng} / \mathrm{L}$ for NTproBNP would results in a negative predictive value of over $99 \%$, but at the cost of many more echocardiograms. ${ }^{8}$

\section{Variation in the cut-off levels on echocardiography}

The description and cut points of abnormality of function in heart failure with normal ejection fraction is defined by expert consensus. It includes (a) a (nearly) normal ejection fraction, (b) left atrial enlargement, (c) increased left ventricular mass or wall thickness, and (d) raised left ventricle filling pressures (fig $2 \Downarrow$ ). ${ }^{10}$ The European Society for Cardiology (ESC) and the National Institute for Health and Care Excellence (NICE) define the cut-off point for a "normal" ejection fraction as $50 \%,{ }^{12}$ but others suggest $45 \%$. There is some support for introducing an "in between" category with an ejection fraction of 40-50\%. ${ }^{411}$ Assessing diastolic function in patients with atrial fibrillation is even more unclear as measuring left ventricle filling is particularly difficult.

\section{What is the prevalence of heart failure with normal ejection fraction?}

There is uncertainty about the prevalence of heart failure in the general adult population, with reported rates of $1 \%$ to $4 \% .^{12} 13$ The prevalence and type of heart failure vary according the population sampled. Reports based mostly on retrospective data in hospitalised patients ${ }^{14}{ }^{15}$ suggest that around $50 \%$ of patients with heart failure have a normal ejection fraction and $50 \%$ have reduced ejection fraction, with a time trend towards an increase in heart failure with normal ejection fraction.

Population prevalence data among in adults $\geq 65$ years old living in the community with heart failure found that around $75 \%$ had a normal ejection fraction and $25 \%$ had a reduced ejection fraction. ${ }^{16}$

\section{What is the aetiology?}

There is general consensus that longstanding hypertension is the commonest precursor to heart failure with normal ejection fraction; as the main arteries stiffen, they reflect the systolic pressure wave instead of absorbing it, contributing to left ventricular pressure overload. ${ }^{3}$ However, there is debate about whether other comorbidities are the cause of heart failure with normal ejection fraction or its consequence. ${ }^{3}{ }^{17}$ Heart failure with normal ejection fraction might develop over many years in response to obesity, hyperlipidaemia, type 2 diabetes, COPD, and chronic kidney disease. ${ }^{3}$ These conditions are associated with low grade systemic inflammation and may cause coronary microvascular endothelial dysfunction, thus triggering myocardial hypertrophy and stiffening as well as interstitial fibrosis. $^{3}$

The uncertainty matters to patients: if these (or other) comorbidities cause heart failure with normal ejection fraction, then they should be intensively managed before the condition develops.

\section{What is the prognosis?}

The prognosis of patients with heart failure with normal ejection fraction depends on the severity of the disease. Around one in 10 will have died five years after diagnosis, rising to around one in three for cases first detected during hospitalisation. ${ }^{18} 19$ As a comparison, the five year mortality of colon cancer is around one in three.

A long term, hospital based, observational study found a lower cardiovascular mortality in patients with heart failure with normal ejection fraction compared with heart failure with reduced ejection fraction (adjusted hazard ratio 0.79 (95\% confidence interval 0.67 to 0.95 ). There was no difference in non-cardiovascular mortality. ${ }^{15}$ An individual patient data analysis of 31 studies (both hospital based observational studies and randomised controlled trials) found an adjusted hazard ratio for all-cause mortality of 0.68 (0.64 to 0.71$)$ for heart failure with normal ejection fraction compared with heart failure with reduced ejection fraction. ${ }^{18}$ Among patients over 60 years old with type 2 diabetes and living in the community who were screened for heart failure, all-cause mortality in newly detected cases of heart failure with normal ejection fraction was also lower than that for heart failure with reduced ejection fraction (1.51 v 3.31 per 100 person years). ${ }^{19}$

\section{How should it be managed?}

No therapy significantly improves survival or prevents hospitalisations in patients with heart failure with normal ejection fraction. ${ }^{12}$ Four large randomised controlled trials of drugs counteracting the renin-angiotensin system (RAS) showed no clear impact on survival. ${ }^{20-23}$ However, the trial inclusion criteria meant that healthy people might have been included because no clear criteria for echocardiographic diastolic dysfunction were applied, and natriuretic peptides were not used as an inclusion criterion. ${ }^{20-23}$

The quality of life of patients with heart failure with normal ejection fraction may be improved by exercise training, according to a recent meta-analysis of six randomised controlled trials (276 patients combined), but its validity is questionable given the small sample size. ${ }^{24}$ 


\section{What should we do in the light of the uncertainty?}

\section{Assessment}

In older people with shortness of breath, consider heart failure with normal ejection fraction as a potential cause. Offer the following diagnostic work-up (based on expert consensus and the available evidence). ${ }^{12}$

- History and clinical examination. In patients with suspected heart failure and previous myocardial infarction, NICE recommends echocardiography with specialist assessment within two weeks. ${ }^{2}$

- Measurement of serum natriuretic peptide levels in patients with no previous myocardial infarction. If BNP level is $>400 \mathrm{ng} / \mathrm{L}$ or NTproBNP > $2000 \mathrm{ng} / \mathrm{L}$, NICE recommends echocardiography and specialist assessment within two weeks; if BNP level is 100-400 $\mathrm{ng} / \mathrm{L}$ or NTproBNP is 400-2000 ng/L, assessment should be within six weeks. ${ }^{2}$

- Echocardiography in both of the above situations is to confirm or exclude heart failure, to differentiate normal and reduced ejection fraction, and to assess valvular heart disease.

- Consider alternative diagnoses and therefore additional tests where relevant-such as electrocardiography, chest radiography, lung function tests, urine analysis, full blood count and film, renal and liver function tests, thyroid stimulating hormone level, and plasma glucose and serum lipid levels. ${ }^{2}$

\section{Management}

Offer people with a confirmed diagnosis of heart failure with normal ejection fraction diuretics titrated to symptoms (treatment based on consensus opinion). Hypertension and other comorbidities should be adequately managed. Consider encouraging exercise after reassuring patients it is safe.

Contributors: All authors searched the literature for background content. FHR provided a primary care perspective. All authors contributed to the design, interpretation of data, and drafting of the manuscript. All are accountable for all aspects of the work and approve the final version, and FHR acts as guarantor.

Competing interests: We have read and understood the BMJ policy on declaration of interests and have no relevant interests to declare.

Provenance and peer review: Commissioned; externally peer reviewed.

1. McMurray JJ, Adamopoulos S, Anker SD, et al. ESC Committee for Practice Guidelines. ESC guidelines for the diagnosis and treatment of acute and chronic heart failure 2012. Eur Heart J 2012;33:1787-847. doi:10.1093/eurhearti/ehs104 pmid:22611136.

2 National Institute Health and Clinical Excellence. Chronic heart failure: management of adults with chronic heart failure in primary and secondary care (partial update). (Clinical guideline 108.) 2010. www.nice.org.uk/CG108.

3 Paulus WJ, Tschöpe C. A novel paradigm for heart failure with preserved ejection fraction: comorbidities drive myocardial dysfunction and remodeling through coronary microvascular endothelial inflammation. J Am Coll Cardiol 2013;62:263-71. doi:10.1016/.jacc.2013.02. 092 pmid:23684677.

4 Rutten FH, Moons KG, Cramer MJ, et al. Recognising heart failure in elderly patients with stable chronic obstructive pulmonary disease in primary care: cross sectional diagnostic study. BMJ 2005;331:1379. doi:10.1136/bmj.38664.661181.55 pmid:16321994.

5 Ingle L, Cleland JGF, Clark AL. Perception of symptoms is out of proportion to cardiac pathology in patients with "diastolic heart failure". Heart 2008;94:748-53. doi:10.1136/hrt. 2007.131144 pmid: 18070942

6 Caruana L, Petrie MC, Davie AP, McMurray JJ. Do patients with suspected heart failure and preserved left ventricular systolic function suffer from "diastolic heart failure" or from misdiagnosis? A prospective descriptive study. BMJ 2000;321:215-8. doi:10.1136/bmj. 321.7255.215 pmid: 10903655 .

7 van Mourik Y, Rutten FH, Moons KG, Bertens LC, Hoes AW, Reitsma JB. Prevalence and underlying causes of dyspnoea in older people: a systematic review. Age Ageing 2014;43:319-26. doi:10.1093/ageing/afu001 pmid:24473156.

8 Taylor CJ, Roalfe AK, Tait L, et al. Observational longitudinal cohort study to determine progression to heart failure in a screened community population: the Echocardiographic Heart of England Screening Extension (ECHOES-X) study. BMJ Open 2014;4:e005256. doi:10.1136/bmjopen-2014-005256 pmid:25015472.

9 Maisel AS, Shah KS, Barnard D, et al. How B-Type Natriuretic Peptide (BNP) and body weight changes vary in heart failure with preserved ejection fraction compared with reduced ejection fraction: Secondary results of the HABIT (HF Assessment With BNP in the Home) Trial. J Card Fail 2015;S1071-9164(15)01120-3.pmid:26433086.

10 Paulus WJ, Tschöpe C, Sanderson JE, et al. How to diagnose diastolic heart failure: a consensus statement on the diagnosis of heart failure with normal left ventricular ejection fraction by the Heart Failure and Echocardiography Associations of the European Society of Cardiology. Eur Heart J 2007;28:2539-50. doi:10.1093/eurhearti/ehm037 pmid: 17428822 .

11 Lam CS, Solomon SD. The middle child in heart failure: heart failure with mid-range ejection fraction (40-50\%). Eur J Heart Fail 2014;16:1049-55. doi:10.1002/ejhf.159 pmid: 25210008.

12 Mosterd A, Hoes AW. Clinical epidemiology of heart failure[Review]. Heart 2007:93:1137-46. doi:10.1136/hrt.2003.025270 pmid:17699180.

13 van Riet EE, Hoes AW, Wagenaar KP, Limburg A, Landman MA, Rutten FH. Epidemiology of heart failure: the prevalence of heart failure and ventricular dysfunction in older adults over time. A systematic review. Eur J Heart Fail 2016;18:242-52. doi:10.1002/ejhf.483 pmid: 26727047.

14 Owan TE, Hodge DO, Herges RM, Jacobsen SJ, Roger VL, Redfield MM. Trends in prevalence and outcome of heart failure with preserved ejection fraction. $N$ Engl J Med 2006;355:251-9. doi:10.1056/NEJMoa052256 pmid:16855265.

15 Gerber Y, Weston SA, Redfield MM, et al. A contemporary appraisal of the heart failure epidemic in Olmsted County, Minnesota, 2000 to 2010. JAMA Intern Med 2015;175:996-1004. doi:10.1001/jamainternmed.2015.0924 pmid:25895156.

16 Mureddu GF, Agabiti N, Rizzello V, et al. PREDICTOR Study Group. Prevalence of preclinical and clinical heart failure in the elderly. A population-based study in Central Italy. Eur J Heart Fail 2012;14:718-29. doi:10.1093/eurjhf/hfs052 pmid:22562498.

17 Senni M, Paulus WJ, Gavazzi A, et al. New strategies for heart failure with preserved ejection fraction: the importance of targeted therapies for heart failure phenotypes. Eur Heart J 2014;35:2797-815. doi:10.1093/eurhearti/ehu204 pmid:25104786.

18 Meta-analysis Global Group in Chronic Heart Failure (MAGGIC). The survival of patients with heart failure with preserved or reduced left ventricular ejection fraction: an individual patient data meta-analysis. Eur Heart J 2012;33:1750-7. doi:10.1093/eurheartj/ ehr254 pmid:21821849.

19 Boonman-de Winter LJ, Hoes AW, Cramer MJ, de Jongh G, Janssen RR, Rutten FH. Prognosis of screen-detected heart failure with reduced and preserved ejection fraction in patients with type 2 diabetes. Int J Cardiol 2015;185:162-4. doi:10.1016/j.ijcard.2015. 03.120 pmid:25796002.

20 Cleland JG, Tendera M, Adamus J, Freemantle N, Polonski L, Taylor J. PEP-CHF Investigators. The perindopril in elderly people with chronic heart failure (PEP-CHF) study. Eur Heart J 2006;27:2338-45. doi:10.1093/eurheartj/ehl250 pmid:16963472.

21 Yusuf S, Pfeffer MA, Swedberg K, et al. CHARM Investigators and Committees. Effects of candesartan in patients with chronic heart failure and preserved left-ventricular ejection fraction: the CHARM-Preserved Trial. Lancet 2003;362:777-81. doi:10.1016/S0140-6736 03)14285-7 pmid:13678871.

22 Massie BM, Carson PE, McMurray JJ, et al. I-PRESERVE Investigators. Irbesartan in patients with heart failure and preserved ejection fraction. N Engl J Med 2008;359:2456-67. doi:10.1056/NEJMoa0805450 pmid:19001508.

23 Pitt B, Pfeffer MA, Assmann SF, et al. TOPCAT Investigators. Spironolactone for heart failure with preserved ejection fraction. N Engl J Med 2014;370:1383-92. doi:10.1056/ NEJMoa1313731 pmid:24716680

24 Pandey A, Parashar A, Kumbhani DJ, et al. Exercise training in patients with heart failure and preserved ejection fraction: meta-analysis of randomized control trials. Circ Heart Fail 2015;8:33-40. doi:10.1161/CIRCHEARTFAILURE.114.001615 pmid:25399909.

Published by the BMJ Publishing Group Limited. For permission to use (where not already granted under a licence) please go to http://group.bmj.com/group/rights-licensing/ permissions 


\section{Is ongoing research likely to provide relevant evidence?}

We searched http://clinicaltrials.gov databases and found several ongoing trials evaluating different drugs targeting different potential mechanisms in heart failure with normal ejection fraction:

- Inhibiting myocardial fibrosis

- Blocking interleukin-1

- Vasodilation

- Blocking the renin-angiotensin system together with inhibition of neprilysin with sacubitril valsartan

We also found trials evaluating:

- Exercise training

- Renal denervation

- Optimal management of comorbidities.

Other research will explore:

- The process of normal ageing of the healthy heart, and the differentiation of heart failure with normal ejection fraction from normal ageing

- Refined diagnostic criteria for heart failure with normal ejection fraction

\section{Recommendations for further research}

- To define the normal ranges of echocardiographic variables at different ages in a large, representative sample of community dwelling older people

- To develop robust diagnostic criteria for defining heart failure with normal ejection fraction

- To apply the diagnostic criteria to community dwelling adults to define the true prevalence and prognosis of heart failure with normal ejection fraction

- To apply the diagnostic criteria to participants in clinical trials evaluating drug therapy in heart failure with normal ejection fraction

- To determine the mechanisms underlying the development of heart failure with normal ejection fraction. Uncovering the pathobiology may reveal treatment pathways

- To design randomised controlled trials for patients with heart failure with normal ejection fraction with robust inclusion criteria: to investigate appropriate drugs, to compare interventions with usual care and placebo, and to evaluate the outcomes of mortality and hospitalisations

\section{How patients were involved in the creation of the article}

We discussed drafts of the paper with two elderly patients with heart failure with normal ejection fraction who provided input. They stressed that, by knowing the cause of their shortness of breath and how to cope with episodes of breathlessness, they felt able to manage their symptoms in daily life and avoid being hospitalised.

\section{Figures}

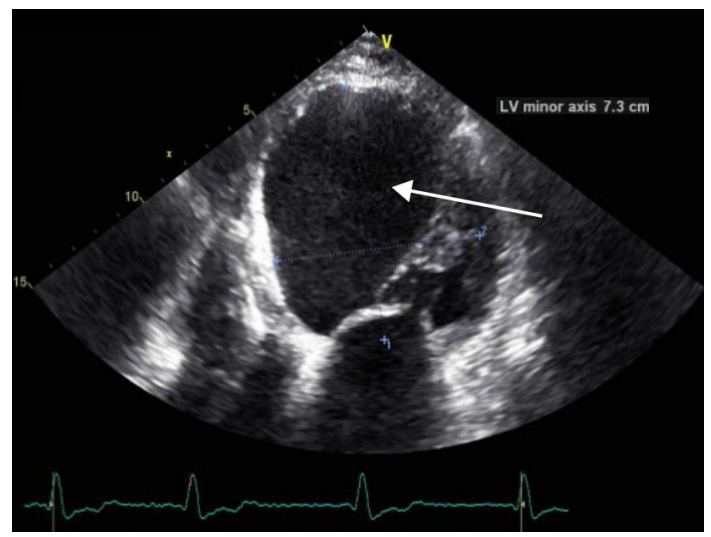

Fig 1 Echocardiogram of an elderly man with previous myocardial infarct and heart failure with reduced ejection fraction. The left ventricle is dilated (upper limit of normal for minor axis is $5.5 \mathrm{~cm}$ ) and globular (arrow). Left ventricular ejection fraction was $24 \%$ 


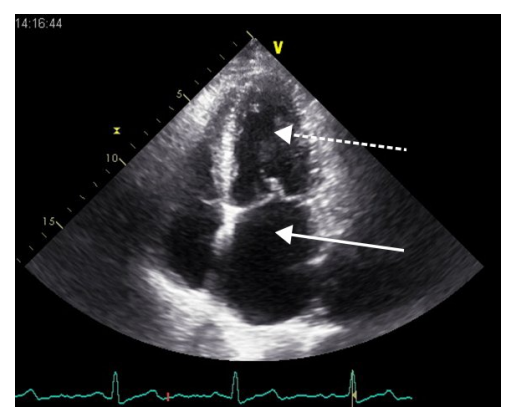

Fig 2 Echocardiogram of an elderly man with breathlessness. Diagnosis of heart failure with normal ejection fraction was made based on the combination of symptoms, a raised concentration of N-terminal B-type natriuretic peptide (NTproBNP), and a dilated left atrium (white arrow). Note that the left atrium is a similar size to the left ventricle (broken arrow). Left ventricular ejection fraction was $62 \%$ 